\title{
SENSOÂRSS \\ Quantum Dot Nanotoxicity Investigations Using Human Lung Cells and TOXOR Electrochemical Enzyme Assay Methodology
}

Tony O’Hara, ${ }^{\dagger}$ Brian Seddon, ${ }^{\ddagger}$ Andrew O’Connor, ${ }^{\S}$ Siobhán McClean, ${ }^{\S}$ Baljit Singh, ${ }^{\ddagger}$ Emmanuel Iwuoha," Xolile Fuku," and Eithne Dempsey, ${ }^{* \dagger, \$ 0}$

${ }^{\dagger}$ Centre for Research in Electroanalytical Technology (CREATE) and ${ }^{\S}$ Centre for Microbial Host Interaction (CHMI), Department of Science, and ${ }^{\ddagger}$ MiCRA-Biodiagnostics Technology Gateway, CASH-Synergy Centre, Institute of Technology Tallaght, Dublin 24, Ireland

"SensorLab, Department of Chemistry, University of the Western Cape, Private Bag X17, Bellville, 7535, South Africa

Supporting Information

ABSTRACT: Recent studies have suggested that certain nanomaterials can interfere with optically based cytotoxicity assays resulting in underestimations of nanomaterial toxicity. As a result there has been growing interest in the use of whole cell electrochemical biosensors for nanotoxicity applications. Herein we report application of an electrochemical cytotoxicity assay developed in house (TOXOR) in the evaluation of toxic effects of mercaptosuccinic acid capped cadmium telluride quantum dots (MSA capped CdTe QDs), toward mammalian cells. MSA capped CdTe QDs were synthesized, characterized, and their cytotoxicity toward A549 human lung epithelial cells investigated. The internalization of QDs within cells was scrutinized via confocal microscopy. The cytotoxicity assay is based on the

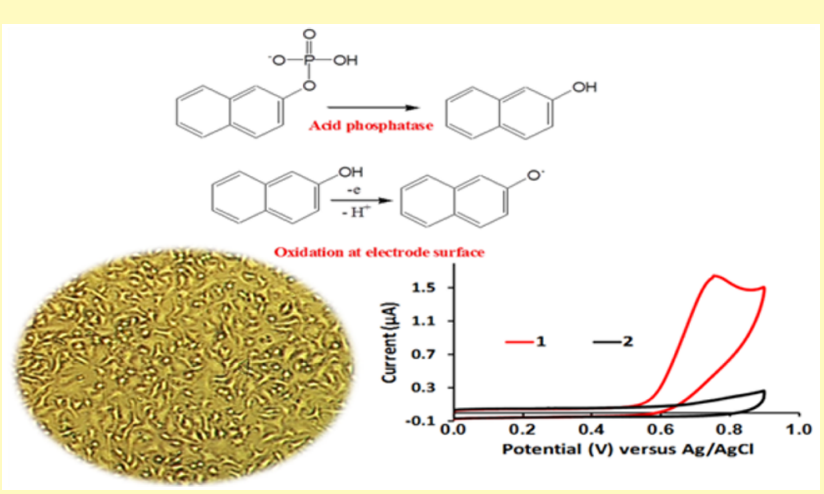
measurement of changes in cellular enzyme acid phosphatase upon $24 \mathrm{~h}$ exposure to QDs. Acid phosphatase catalyzes dephosphorylation of 2-naphthyl phosphate to 2-naphthol (determined by chronocoulometry) and is indicative of metabolic activity in cells. The $24 \mathrm{~h}$ IC50 (concentration resulting in 50\% reduction in acid phosphatase activity) value for MSA capped CdTe QDs was found to be $118 \pm 49 \mu \mathrm{g} / \mathrm{mL}$ using the TOXOR assay and was in agreement with the MTT assay (157 $\pm 31 \mu \mathrm{g} /$ $\mathrm{mL}$ ). Potential uses of this electrochemical assay include the screening of nanomaterials, environmental toxins, in addition to applications in the pharmaceutical, food, and health sectors.

KEYWORDS: cytotoxicity, electrochemical, biosensors, quantum dot, nanotoxicity

Ds are inorganic nanoparticles whose electrons and holes are quantum confined in three spatial dimensions. These unique semiconductors are emerging as alternative materials for displays, solar energy harvesting, and as complementary tools to organic fluorescent dyes for biological imaging. ${ }^{2,3}$ QDs are composed of groups III-V (InP, InAs), groups II-VI ( CdS, CdTe), or group IV ( $\mathrm{Si}, \mathrm{Ge})$ elements. ${ }^{4-6}$ The metal core is often covered or capped with an inorganic shell such as zinc sulfide and the particle coated with organic agents such as thioglycolic acid (TGA) in order to improve physiochemical properties and biocompatibility. ${ }^{1,7-11}$ One of the advantages of QD nanomaterials over organic fluorescent dyes is their broad absorption characteristics and narrow emission profiles, a property which allows simultaneous, multiple color formation using a single light source. ${ }^{12,13}$ Owing to their intended industrial uses, biological systems are most likely exposed to these small-scale nanomaterials. ${ }^{14}$

To date there have been numerous reports suggesting that cadmium-based QDs are cytotoxic, hence limiting their applicability. ${ }^{3,11,14-17}$ Toxicity appears to stem from the release of $\mathrm{Cd}^{2+}$ ions from the core due to imperfections in the surface which follow particle internalization by the cell. ${ }^{18} \mathrm{Cd}^{2+}$ is known to generate reactive oxygen species, the ion can affect mitochondrial function, damage DNA and induce apoptosis or cell death. Other properties of QDs believed significant to cytotoxicity include particle size, surface chemistry, and charge. $^{14}$

For the most part, the cell toxicity of QDs and other nanomaterials has been assessed by colorimetric assays such as the 3-(4,5-dimethylthiazol-2-yl)-2,5-diphenyl tetrazolium bromide (MTT) and lactate dehydrogenase (LDH) assays ${ }^{2,11,14-16}$ with cellular internalization confirmed via confocal or transmission electron microscopy (TEM). ${ }^{19,20}$ However, concerns have been raised that some nanomaterials can interfere with the colorimetric dyes used in cytotoxicity assays. ${ }^{21-23}$

In recent times attention has turned to electrochemical methods for cytotoxicity evaluation. Electric cell substrate

Received: October 26, 2016

Accepted: December 21, 2016

Published: January 5, 2017 
impedance (ECIS) techniques have been used to evaluate the cytotoxicity of a variety of nanomaterials ${ }^{24-32}$ with a number of advantages including suitability for high throughput screening and allowing for continuous online monitoring of cell viability throughout the exposure period (not possible with conventional end point cytotoxicity assays).

Other interesting whole-cell electrochemical biosensing technologies have also been developed to probe the toxicity of nanomaterials. Yoon et al. developed an electrochemical biosensor that measured concentration, size, and time-dependent cytotoxicity of graphene nanoflakes toward HeLa cells. ${ }^{33}$ An ITO working electrode modified with a graphene/nafion nanocomposite film measured increased hydrogen peroxide release from cells upon exposure to graphene nanoflakes. Kim et al. reported an electrochemical cell chip to assess the cytotoxicity of $\mathrm{CdSe} / \mathrm{ZnS}$ QDs. With the aid of differential pulse voltammetry, the device measured changes in the intracellular redox environment of human neuroblastoma cells and showed greater sensitivity when compared with the MTT assay. ${ }^{34}$ One of the drawbacks of many such whole-cell electrochemical biosensing systems developed for cytotoxicity measurements is that they provide little direct information on the mode of action of toxins within the cell compared to the established MTT, LDH, and neutral red uptake assays. This disadvantage highlights the need for an electrochemical assay that provides greater insights into inhibiting effects of toxins toward cells.

Acid phosphatases are a family of enzymes belonging to the hydrolase class and catalyze the hydrolysis of orthophosphate monoesters under acidic conditions. ${ }^{35}$ They are found widely in plants, animals, and microorganisms and play a role in the production, transport, and recycling of inorganic phosphate which is crucial to cellular metabolism and bioenergetics. ${ }^{36}$ They are located in the cell membrane, cytosol, and lysosomes, ${ }^{37}$ and a number of researchers have reported making optical measurements of changes in these enzymes' activity upon exposure of cells to cytotoxic drugs ${ }^{38}$ and cigarette smoke condensate. ${ }^{39}$

In our previous work we reported the TOXOR electrochemical cytotoxicity assay, which makes electrochemical measurements of changes in intracellular acid phosphatase upon exposure to toxic chemicals. ${ }^{40}$ Acid phosphatase converts substrate 2-naphthyl phosphate to 2-naphthol which is oxidized at a carbon electrode surface. Electrochemical detection of acid phosphatase offers a number of advantages such as high sensitivity, low cost, and potential for incorporation of the assay into a portable sensing device. In this paper we examine nanotoxicity screening applications of this electronic assay. MSA capped CdTe QDs were selected for initial screening in order to prove the capability of the electrochemical assay with respect to cytotoxicity measurements of a nanoparticle previously reported as being cytotoxic toward mammalian cells. ${ }^{17,41}$ To the best of our knowledge this is the first such report of an electrochemical cytotoxicity assay for QDs based on this approach and validated against the MTT assay. This assay could be a useful tool for cytotoxicity screening of QDs as well as other nanomaterials.

\section{EXPERIMENTAL SECTION}

Materials. Cadmium chloride $\left(\mathrm{CdCl}_{2}, 99.99 \%\right)$, sodium borohydride (98\%), tellurium powder (99.99\%), MSA ( $\geq 99.99 \%)$, phosphate buffered saline (PBS) tablets, Roswell Park Memorial Institute (RPMI) medium containing $25 \mathrm{mM}$ HEPES, trypsin 0.5\%-EDTA
$0.2 \%$, L-glutamine, sodium acetate ( $>99 \%)$, and magnesium chloride hexahydrate were all purchased from Sigma-Aldrich. Fetal bovine serum (FBS) was supplied by Biochrom while penicillin/streptomycin $100 \times$ was from Applichem GmBH. All reagents used for cell culture were tissue culture grade. Other chemicals and suppliers included acetic acid (99\% Riedel de Haen) and $0.22 \mu \mathrm{m}$ cellulose acetate filters (GE-Whatman). Uvasol potassium bromide for IR spectroscopy and acetone (99.8\%) were Merck brand. Deionized water was prepared using an ELGA PURELAB Option-S-7BP water purification system. Electrochemical sensors $(30 \mathrm{~mm} \times 8 \mathrm{~mm})$ were fabricated using screen printing (DEK 248) on polyester strips. Sensors were designed with electrodes, including carbon and silver $(\mathrm{Ag} / \mathrm{AgCl})$ films (Gwent Ltd.) and a sensing area of $4 \mathrm{~mm}^{2}$.

Synthesis of MSA Capped CdTe QDs. MSA capped CdTe QDs were prepared following a modified version of the procedure reported by Vaishnavi and Renganathan. ${ }^{42} \mathrm{~A}$ typical synthesis involved dissolution of the metal precursor $\mathrm{CdCl}_{2}(2 \mathrm{mmol})$, MSA (0.7 $\mathrm{mmol}$ ) in $50 \mathrm{~mL}$ deionized water, and adjusting the $\mathrm{pH}$ to 12 with $1 \mathrm{M}$ $\mathrm{NaOH}$ followed by mixing at room temperature for 30 min under nitrogen. Separately, a $50 \mathrm{~mL}$ solution of $\mathrm{NaHTe}$ was prepared in a 3neck round-bottom flask via reduction of Te powder $(0.5 \mathrm{mmol})$ with $\mathrm{NaBH}_{4}(13 \mathrm{mmol})$ under nitrogen at $0{ }^{\circ} \mathrm{C}$ for $6 \mathrm{~h}$. The purple/gray colored $\mathrm{NaHTe}$ was added slowly to the $\mathrm{CdCl}_{2}$ precursor solution and then refluxed under nitrogen for $2 \mathrm{~h}$ at $100{ }^{\circ} \mathrm{C}$ resulting in the formation of a green colored suspension. Following reflux, the roundbottom flask was cooled on ice and $100 \mathrm{~mL}$ acetone added slowly while mixing. The precipitated QDs were collected by centrifugation (11 $000 \mathrm{rpm}, 5 \mathrm{~min}$ ) and washed with acetone (3 times) followed by deionized water and then dried in an oven at $60{ }^{\circ} \mathrm{C}$.

Characterization. UV-visible absorption spectra of QDs dispersed in DI water were recorded using a Hitachi U-2900 spectrophotometer. Fluorescence excitation and emission spectra were measured using a LS55 luminescence spectrophotometer, scan speed $500 \mathrm{~nm} / \mathrm{min}$, slit width $7.5 \mathrm{~nm}$. Fourier transformed infrared (FTIR) spectra $\left(400-4000 \mathrm{~cm}^{-1}\right)$ of QDs and MSA capping agent in $\mathrm{KBr}$ disks were obtained using an IR Prestige-21 Shimadzu spectrometer. Energy dispersive X-ray (EDX) analysis of QDs was carried out using a JEOL JSM-6390LV SEM instrument with Inca $x$-act (Oxford Instruments plc) EDX detector for elemental composition confirmation. SEM/EDX sample preparation involved dispersion of QDs in deionized water followed by sonication and drop casting onto an aluminum stub with samples dried overnight before analysis. Size distribution and selected area electron diffraction (SAED) pattern analysis were performed using a JEOL JEM-2100F transmission electron microscope (TEM) operating at $200 \mathrm{kV}$. Sample preparation for TEM involved drop casting a suspension of QDs $(\sim 5 \mu \mathrm{L})$ onto carbon coated 200 mesh $\mathrm{Cu}$ grids followed by drying at room temperature. Powder X-ray diffraction (XRD) analysis of QDs was performed using a Rigaku D/MAX-PC 2500 X-ray diffractometer with a CuKa $(\theta=1.54 \AA)$ radiation source operating at $40 \mathrm{kV}$ and $200 \mathrm{~mA}$. MTT cytotoxicity assay absorbance measurements were made using a Biotek Synergy H1 Hybrid Reader. Electrochemical measurements of cellular acid phosphatase were made using a $\mathrm{CH}$ Instruments Inc. CHI630C potentiostat with screen-printed sensors. Agglomeration of QDs after $24 \mathrm{~h}$ suspension in cell culture medium was investigated by dynamic light scattering (DLS) using a Malvern instruments ZetaSizer Nanosizer.

Cell Culture. A549 human lung epithelial cells were cultured in T75 polystyrene tissue culture flasks containing RPMI medium plus 25 $\mathrm{mM}$ HEPES, 10\% FBS, 1\% L-glutamine, and 1\% penicillin/ streptomycin. The cells were grown in a $5 \% \mathrm{CO}_{2}$ atmosphere at 37 ${ }^{\circ} \mathrm{C}$ and were subcultured for a maximum of 20 passages. Prior to carrying out experiments, cells were examined under a light microscope to check they were in the logarithmic phase of growth and free from microbial contamination.

Electrochemical Cytotoxicity Assay. A 96 well plate was seeded with $4 \times 10^{4}$ A549 cells per microwell and incubated for $24 \mathrm{~h}(5 \%$ $\mathrm{CO}_{2}, 37^{\circ} \mathrm{C}$ ). Following incubation, the medium was removed and each microwell washed three times with PBS. Fresh medium $(100 \mu \mathrm{L})$ was added to each microwell plus $100 \mu \mathrm{L}$ of MSA capped CdTe QDs 
$(0-1000 \mu \mathrm{g} / \mathrm{mL})$. QDs were presterilized by exposure to UV light $(254 \mathrm{~nm})$ for $20 \mathrm{~min}$ before dispersion in sterile deionized $\mathrm{H}_{2} \mathrm{O}$. This approach was employed as previous attempts to sterilize suspensions of QDs using a $0.2 \mu \mathrm{m}$ cellulose acetate filter resulted in loss of some material during filtration. Cells were exposed to QDs for $24 \mathrm{~h}$ after which time the particles were removed. The microwells were then gently washed three times with PBS followed by the addition of 10 $\mathrm{mM}$ 2-naphthyl phosphate in $\mathrm{pH} 4.5$ acetate buffer, presterilized using a $0.22 \mu \mathrm{m}$ filter. After $1 \mathrm{~h}$, the supernatant was removed and pipetted into fresh microwells. Generation of 2-naphthol arising from cellular acid phosphatase activity was measured using chronocoulometry. Chronocoulometry involved a potential step of 0.2 to $0.8 \mathrm{~V}$ versus $\mathrm{Ag}$ / $\mathrm{AgCl}$ and a pulse width of $10 \mathrm{~s}$. The charge at $10 \mathrm{~s}$ was used for cytotoxicity analysis. All cytotoxicity measurements were undertaken in triplicate and in three independent experiments. For each experiment, the IC50 value was determined by fitting the data with a four parameter nonlinear fit using GraphPad Prism 7 software. In order to test for potential interference of QDs with the signal from the cytotoxicity assay, the experiment was repeated following the same procedure with microwells filled with cell culture medium only (Supporting Information page S5).

MTT Cytotoxicity Assay. The cytotoxicity of QDs was also assessed using the colorimetric MTT cytotoxicity assay kit (Cayman Chemical Company). A549 cells were seeded on a 96 well plate and exposed to the nanoparticles as previously described. Following a period of $24 \mathrm{~h}$ incubation, $10 \mu \mathrm{L}$ of $5 \mathrm{mg} / \mathrm{mL}$ MTT reagent was added to each sample. The plate was placed on an orbital shaker for $1 \mathrm{~min}$ and then incubated for $4 \mathrm{~h}$ in a tissue culture incubator $\left(5 \% \mathrm{CO}_{2}, 37^{\circ}\right.$ C). After this time the toxin and medium were removed from the microwells and $100 \mu \mathrm{L}$ of crystal dissolving solution was added to each well. The plate was then placed on an orbital shaker for $5 \mathrm{~min}$ and subsequently incubated at $37{ }^{\circ} \mathrm{C}$ for $10 \mathrm{~min}$ to ensure dissolution of formazan crystals. Formazan generation by cells was measured at 570 $\mathrm{nm}$. Following each experiment, the IC50 value at $24 \mathrm{~h}$ was determined. Potential interference of nanoparticles with the cytotoxicity assay was also investigated by repeating the experiment in the absence of cells (Supporting Information page S5).

Cellular Uptake of MSA Capped CdTe QDs. Internalization of QDs by cells was investigated using an Olympus Flouview FV 1000 confocal microscope. Briefly, $100 \mu \mathrm{L}$ volumes of cell suspension $(4 \times$ $10^{5}$ cells per $\mathrm{ml}$ ) were aliquoted into four wells of an eight well glass cover slide (Nunc Lab-Tech) and incubated for $24 \mathrm{~h}\left(37^{\circ} \mathrm{C}\right.$, 5\% $\mathrm{CO}_{2}$ ). After $24 \mathrm{~h}$, the medium was removed and the wells washed with PBS (three times, $100 \mu \mathrm{L}$ each) followed by the addition of $100 \mu \mathrm{L}$ of fresh RPMI medium. Aliquots, $100 \mu \mathrm{L}$ of MSA capped CdTe QDs $(600 \mu \mathrm{g} / \mathrm{mL})$ dispersed in PBS, were added to two wells while $100 \mu \mathrm{L}$ aliquots of PBS were added to two additional wells containing cells as a control. After $30 \mathrm{~min}$, QDs and cell culture medium were removed from the wells which were subsequently washed with PBS (three times, $100 \mu \mathrm{L}$ each) followed by fixation with $2.5 \% \mathrm{w} / \mathrm{v}$ paraformaldehyde dissolved in PBS. The cells were then stained with DAPI (VECTOR)H-1200) so as to allow visualization of cell nuclei. Confocal images of cells were obtained using three channels (CH1: excitation $405 \mathrm{~nm}$, filter 425 to $491 \mathrm{~nm}$ (DAPI); $\mathrm{CH} 2$ : excitation $405 \mathrm{~nm}$, filter 535 to $580 \mathrm{~nm}$ (MSA capped CdTe QDs); and $\mathrm{CH} 3$ : DIC imaging mode) using $40 \times$ oil immersion lens.

Statistical Analysis. The results of all cytotoxicity experiments were analyzed by one-way ANOVA plus Dunnett's comparison using Minitab 16 statistical software package with $p<0.05$ considered statistically significant.

\section{RESULTS AND DISCUSSION}

Characterization of QDs. TEM analysis (Figure 1a) was performed in order to determine the size distribution of synthesized CdTe nanoparticles. High resolution (HR)-TEM images of QDs (Figure 1b) showed the presence of lattice fringes revealing their crystalline nature. However, in some images the QDs appeared agglomerated. This could possibly be reduced by employing different ligands to cap the nano-
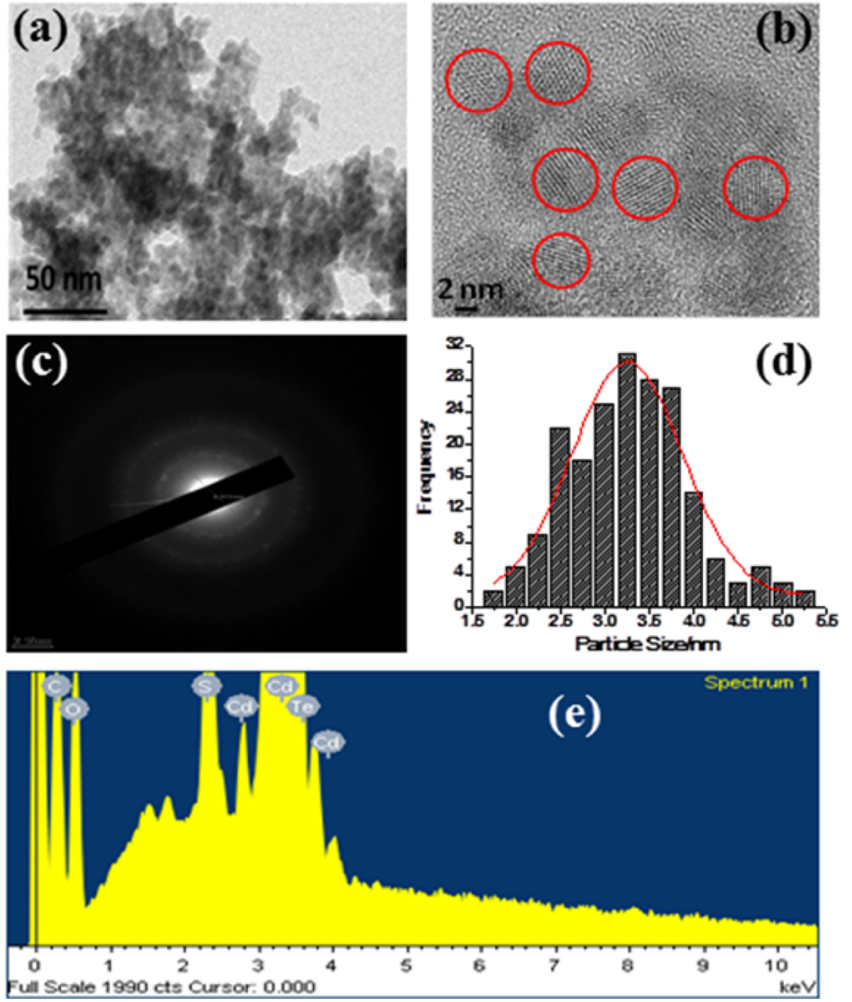

Figure 1. Results from the electron microscopy studies: (a,b) TEM images, (c) SAED pattern, (d) size distribution histogram, (e) EDX spectra of MSA capped CdTe QDs.

particles, e.g., mercaptopropionic acid (MPA). Size distribution analysis (Figure 1d) was performed by measuring 200 particles over randomly selected areas during HR-TEM imaging. Particle size measurements were made with the aid of ImageJ software (http://rsb.info.nih.gov/ij). From this analysis, the average size of the QDs was estimated to be $3.3 \pm 0.7 \mathrm{~nm}$. The QDs were shown to be distributed within a narrow size range with $85 \%$ of the particle population within a $2.1-4.1 \mathrm{~nm}$ size distribution. The interplanar spacing $(d)$ of QDs was investigated using SAED analysis (Figure 1c) and found to be $0.39,0.33$, and 0.24 $\mathrm{nm}$. EDX analysis was performed to confirm the elemental composition of MSA capped CdTe QDs with peaks for Cd, Te, $\mathrm{O}$, and $\mathrm{S}$ detected. This is in agreement with the synthetic composition and supports the formation MSA capped CdTe QDs. After initial washing with acetone (during the synthesis stage), $\mathrm{Na}$ and $\mathrm{Cl}$ peaks were detected in the EDX spectrum. This was due to the presence of unreacted starting materials, suggesting the need for additional washing of the material. Further washing with deionized water removed the unreacted precursors as confirmed by the comparison of EDX analysis before and after washing stages. The final EDX profile is shown in Figure 1e. EDX provided useful insights regarding removal of precursor residues and purity of QDs-crucial when performing cytotoxicity evaluation of any nanomaterial. The presence of such unreacted starting materials may influence and introduce additive or synergistic cytotoxicity toward cells resulting in false observations.

The optical properties of the QDs were examined by UV-vis (Supporting Information Figure S-1) and fluorescence spectroscopy (Figure 2). MSA capped CdTe QDs showed an absorbance at $465 \mathrm{~nm}$, with excitation at this wavelength resulting in a fluorescence emission at $550 \mathrm{~nm}$. The 


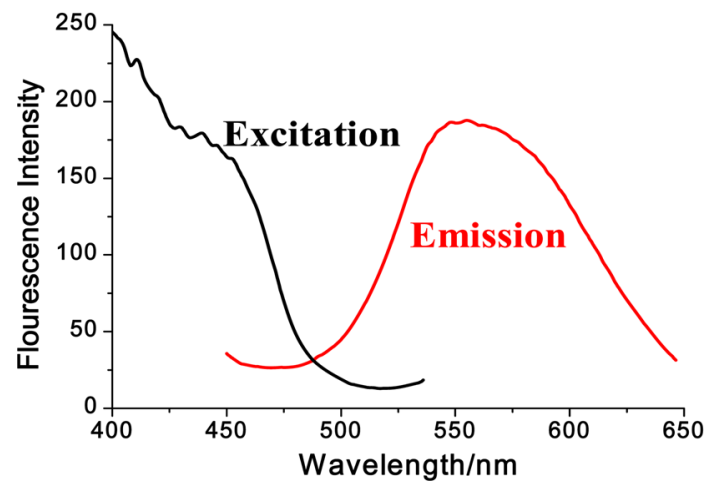

Figure 2. Fluorescence excitation and emission spectra of MSA capped CdTe QDs.

fluorescence properties of QDs is known to depend on particle size with a red shift in emission wavelength occurring with increased particle size due to a reduction in the bandgap energy. ${ }^{16,43}$ Additionally, FTIR analysis confirmed successful capping of QDs with MSA (Supporting Information Figure S2 ). Powder XRD analysis of QDs (Supporting Information Figure S-3) revealed a diffraction pattern that could be indexed to $\mathrm{CdTe}$ crystal phase in agreement with the databases references (CdTe: $04-004-8429$ ). The peaks at $2 \theta^{\circ}$ positions $23.080^{\circ}, 27.620^{\circ}, 38.340^{\circ}, 46.010^{\circ}$, and $62.890^{\circ}$ correspond with the (111), (200), (220), (311), and (420) CdTe crystal planes. Four additional peaks were also evident in the diffraction pattern at $2 \theta$ positions $40.570^{\circ}, 43.440^{\circ}, 49.800^{\circ}$, and $57.010^{\circ}$ which corresponded with the $\mathrm{Cd}_{2} \mathrm{Te}_{3} \mathrm{O}_{9}$ oxide phase.

The presence of this oxide phase was most likely due to surface oxidation of QDs which like other nanoscale particles are very active and prone to surface oxidation. During preparation, the vigorous washings (removal of precursor impurities) with acetone and deionized water could significantly contribute to the oxide phase. Washing was necessary to remove precursor impurities as investigated and confirmed during SEM/EDX studies. It has been previously reported that oxidation of both $\mathrm{CdSe}$ and CdTe QDs can lead to greater release of $\mathrm{Cd}^{2+}$ ions from the core of $\mathrm{QDs}$ giving rise to enhanced cytotoxicity. ${ }^{44,45}$ It is therefore likely that this factor contributed to the cytotoxicity of QDs investigated during this study. The lattice constant (a) for the cubic CdTe phase was found to be $0.66 \mathrm{~nm}$ which was in agreement with literature. ${ }^{46}$ In addition, the interplanar spacings $(d)$ observed from XRD analysis of the (111), (200), and (220) planes were in agreement with those calculated from the SAED-TEM analysis.

Cytotoxicity Assessment. The cytotoxicity of MSA capped CdTe toward human cells was investigated using the electrochemical cytotoxicity assay and the data was correlated with a standard MTT assay. A concentration dependent reduction in acid phosphatase activity was detected in cells following $24 \mathrm{~h}$ exposure to $\geq 50 \mu \mathrm{g} / \mathrm{mL}$ CdTe QDs. The chronocoulometry traces (labeled for different concentrations of particles $(\mu \mathrm{g} / \mathrm{mL}))$ following $24 \mathrm{~h}$ exposure are shown (Figure 3).

A similar concentration dependent decrease in metabolic activity in cells was observed with the MTT assay. For comparison the results of both assays were normalized against untreated control cells (Figure 4a,b). The IC50 values, i.e., the concentration of MSA CdTe QDs resulting in 50\% acid phosphatase or $50 \%$ mitochondrial dehydrogenase inhibition at

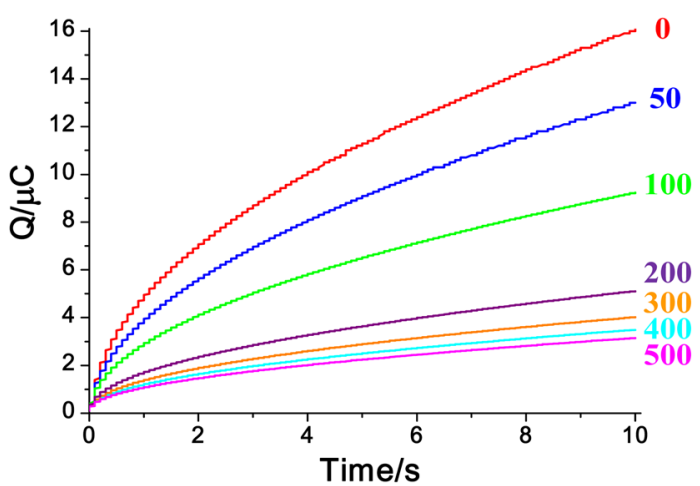

Figure 3. Chronocoulometry data $(0-500 \mu \mathrm{g} / \mathrm{mL})$ following $24 \mathrm{~h}$ exposure to QDs.
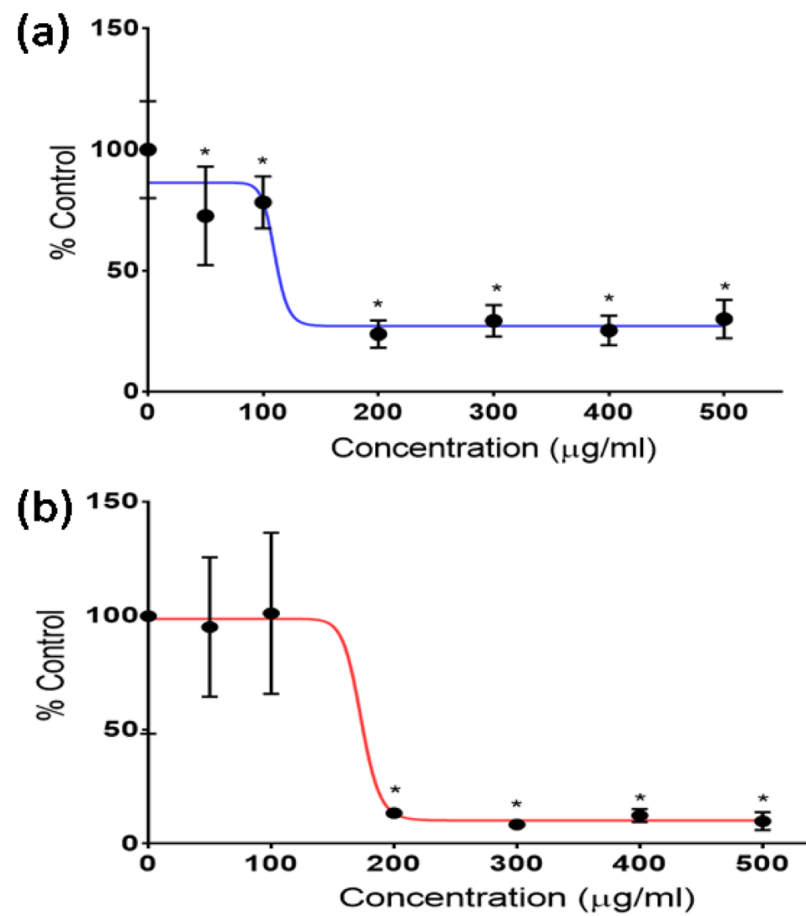

Figure 4. Normalized TOXOR electrochemical (a) and (b) MTT cytotoxicity assay data following $24 \mathrm{~h}$ exposure of A549 cells to QDs $(0-500 \mu \mathrm{g} / \mathrm{mL})$. Results are the mean of three independent experiments. Error bars represent SD $(n=9)$. Data points marked with an asterisk are statistically significant from controls $P<0.05$.

$24 \mathrm{~h}$ were determined from the average of three experiments $(118 \pm 49 \mu \mathrm{g} / \mathrm{mL}$ TOXOR assay and $157 \pm 31 \mu \mathrm{g} / \mathrm{mL}$ MTT cytotoxicity assay). Dynamic light scattering data revealed that after $24 \mathrm{~h}$ suspension in cell culture medium, QDs $(500 \mu \mathrm{g} /$ $\mathrm{mL}$ ) had agglomerated, achieving a particle size of $355.3 \mathrm{~nm}$ (Supporting Information Figure S-4) with zeta potential measurements $(-19.7 \pm 1.9 \mathrm{mV})$ suggesting that the suspended QDs were unstable (below $\pm 30 \mathrm{mV}$ ). ${ }^{14}$ Therefore, agglomeration is likely to have contributed to cytotoxicity toward cells.

With the aid of the MTT assay a number of groups have investigated the toxic properties of CdTe QDs toward mammalian cells with primary cell lines showing the greatest sensitivity. ${ }^{47,48}$ Yan et al. reported a concentration dependent drop in the metabolic activity of primary human umbilical vascular endothelial cells (HUVECs) upon $24 \mathrm{~h}$ exposure to $0.1-100 \mu \mathrm{g} / \mathrm{mL}$ QDs with an IC50 value of $10.06 \mu \mathrm{g} / \mathrm{mL}$, 
while Nguyen et al. examined concentration- and timedependent cytotoxicity of QDs toward human hepatocellular carcinoma cells (HepG2) reporting $75 \%$ reduction in cell viability after $24 \mathrm{~h}$ exposure to $100 \mu \mathrm{g} / \mathrm{mL} .^{11}$

There was no evidence that QDs had interfered with the electrochemical assay signal (Supporting Information Figure S5a). In the case of the MTT assay, increased absorbance (most likely due to adherence of agglomerated QDs to the surface of the microwell during incubation) was measured at $570 \mathrm{~nm}$ in the absence of cells when microwells were filled with $\geq 300 \mu \mathrm{g} /$ $\mathrm{mL}$ of QDs dispersed in cell culture medium (Supporting Information S-5b). However, it is unlikely that these small increases in absorbance $(\leq 0.13 \mathrm{AU})$ had a significant impact on the results of the MTT assays because at $\geq 300 \mu \mathrm{g} / \mathrm{mL}$ concentrations, $\geq 88 \%$ of the metabolic activity in cells was inhibited.

Cellular Uptake of QDs. Confocal microscopy was employed to investigate internalization of MSA capped CdTe QDs within cells. Optical sectioning (Figure 5c) and XZ plane
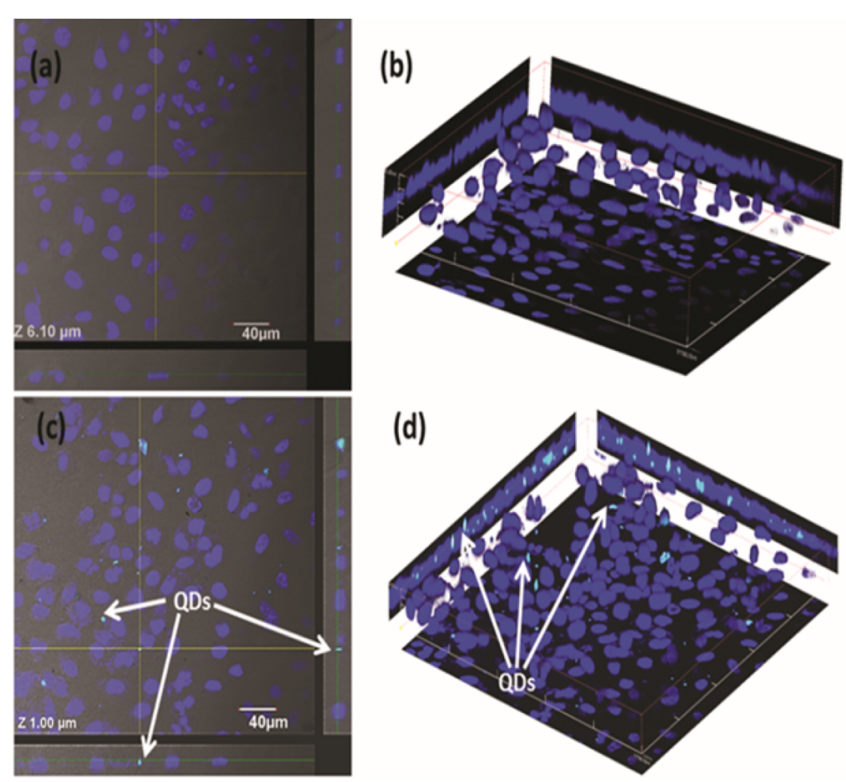

Figure 5. Confocal images of A549 cells following 30 min exposure to either 50/50 RMPI medium and PBS (Control) (a and b) or MSA capped CdTe QDs $(300 \mu \mathrm{g} / \mathrm{mL})$ (c and d). Cell nuclei (blue) were stained using DAPI. Representative optical section at $(1 \mu \mathrm{m})(\mathrm{c})$ and 3D reconstructions (d) both show MSA capped CdTe QDs (green) were evident in cells following $30 \mathrm{~min}$ exposure.

imaging (Figure 5d) shows the entry of QDs within the plane of the cells after as little as $30 \mathrm{~min}$ (presented as green in confocal images), indicating internalization. This was confirmed using phase contrast microscopy (not shown). These findings are supported by the work of a number of researchers who have employed confocal microscopy to investigate internalization of QDs by mammalian cells. ${ }^{3,16}$ Wang et al. studied the time dependent internalization of MSA capped CdTe particles within HeLa cells, reporting the entry of green colored entities into the cytoplasm following $10 \mathrm{~min}$ incubation with the accumulation of bright clusters of particles within cells over time. ${ }^{49} \mathrm{Su}$ et al. investigated the internalization of CdTe QDs in human embryonic kidney cells (HEK cells) and reported shrinkage and deformation of nuclei after $24 \mathrm{~h}$ exposure to particle concentrations on the order of $150 \mathrm{nM}^{50}$ Nano- particles such as QDs are believed to enter cells by both diffusion and endocytosis mechanisms ${ }^{51}$ with factors such as particle size and capping agent influencing cellular uptake.

\section{CONCLUSION}

The cytotoxicity of MSA capped CdTe QDs toward mammalian cells was examined for the first time using an in house TOXOR electrochemical cytotoxicity assay. The $24 \mathrm{~h}$ IC50 value $(118 \pm 49 \mu \mathrm{g} / \mathrm{mL})$ determined by the electrochemical assay was in good agreement with that found using the MTT cytotoxicity assay $(157 \pm 31 \mu \mathrm{g} / \mathrm{mL})$. Importantly there was no evidence that the nanoparticles had interfered with the electrochemical assay signal. Future work will therefore focus on the use of this electrochemical cytotoxicity assay to screen other types of nanomaterials, in particular, those reported to interfere with colorimetric cytotoxicity assay measurements, e.g. CNT and $\mathrm{TiO}_{2}$ nanoparticles. Finally, work is currently underway to develop this assay in more robust fish cell lines with the view to developing a portable biochip for environmental toxicant and nanomaterial screening applications.

\section{ASSOCIATED CONTENT}

\section{S Supporting Information}

The Supporting Information is available free of charge on the ACS Publications website at DOI: 10.1021/acssensors.6b00673.

Additional characterization of QDs including powder Xray diffraction pattern, UV-vis, and FTIR spectra. Results of investigations into potential interference of QDs with electrochemical and MTT cytotoxicity assay signals are also included. (PDF)

\section{AUTHOR INFORMATION}

\section{Corresponding Author}

*E-mail Eithne.Dempsey@ittdublin.ie. Phone +353 14042862.

\section{ORCID}

Eithne Dempsey: 0000-0003-3607-5015

\section{Author Contributions}

The manuscript was written through contributions of all authors. All authors have given approval to the final version of the manuscript.

\section{Notes}

The authors declare no competing financial interest.

\section{ACKNOWLEDGMENTS}

The authors would like to acknowledge the financial support from the Irish Research Council (IRC), Ballsbridge, Dublin 4, Ireland. We also wish to acknowledge the Centre for Applied Sciences for Health (CASH), Insitute of Technology Tallaght, Dublin 24, PRTL1 cycle 4 and the National Development Plan for Ireland for assistance. We wish to acknowledge the assistance of of Dr Yina Guo (TEM analysis) and Dr Wynette Redington (XRD analysis) of the Materials and Surface Science Institute (MSSI), University of Limerick, Ireland. We also acknowledge the help of Dr Alan Casey (DLS analysis) of DIT Nanolab, FOCAS Research Institute, Dublin Institute of Technology, Kevin Street, Dublin 8. 


\section{REFERENCES}

(1) Wang, Y.; Hu, R.; Lin, G.; Roy, I.; Yong, K.-T. Functionalized Quantum Dots for Biosensing and Bioimaging and Concerns on Toxicity. ACS Appl. Mater. Interfaces 2013, 5, 2786-2799.

(2) Luo, Y.-H.; Wu, S.-B.; Wei, Y.-H.; Chen, Y.-C.; Tsai, M.-H.; Ho, C.-C.; Lin, S.-Y.; Yang, C.-S.; Lin, P. Cadmium-Based Quantum Dot Induced Autophagy Formation for Cell Survival via Oxidative Stress. Chem. Res. Toxicol. 2013, 26, 662-673.

(3) Chang, S.; Dai, Y.; Kang, B.; Han, W.; Mao, L.; Chen, D. UVEnhanced Cytotoxicity of Thiol-Capped CdTe Quantum Dots in Human Pancreatic Carcinoma Cells. Toxicol. Lett. 2009, 188, 104111.

(4) Li, Z.; Sun, Q.; Zhu, Y.; Tan, B.; Xu, Z. P.; Dou, S. X. Ultra-Small Fluorescent Inorganic Nanoparticles for Bioimaging. J. Mater. Chem. B 2014, 2, 2793-2818.

(5) Hardman, R. A Toxicologic Review of Quantum Dots: Toxicity Depends on Physicochemical and Environmental Factors. Environ. Health Perspect. 2006, 114, 165-172.

(6) Jamieson, T.; Bakhshi, R.; Petrova, D.; Pocock, R.; Imani, M.; Seifalian, A. M. Biological Applications of Quantum Dots. Biomaterials 2007, 28, 4717-4732.

(7) Wang, J.; Lu, Y.; Peng, F.; Zhong, Y.; Zhou, Y.; Jiang, X.; Su, Y.; $\mathrm{He}$, Y. Photostable Water-Dispersible NIR-Emitting CdTe/CdS/ZnS Core-Shell-Shell Quantum Dots for High-Resolution Tumor Targeting. Biomaterials 2013, 34, 9509-9518.

(8) Dai, M.-Q.; Zheng, W.; Huang, Z.; Lanry Yung, L.-Y. Aqueous Phase Synthesis of Widely Tunable Photoluminescence Emission $\mathrm{CdTe} / \mathrm{CdS}$ Core/shell Quantum Dots under a Totally Ambient Atmosphere. J. Mater. Chem. 2012, 22, 16336.

(9) Asgari, M.; Shanehsaz, M.; Shamsipur, M.; Behzad, M.; Maragheh, M. G. Electrochemical Reduction of Dioxygen on a Thioglycolic Acid-Capped CdTe Quantum Dots Modified Glassy Carbon Electrode. J. Appl. Electrochem. 2013, 43, 15-19.

(10) Zhu, Y.; Li, Z.; Chen, M.; Cooper, H. M.; Lu, G. Q. M.; Xu, Z. P. One-Pot Preparation of Highly Fluorescent Cadmium Telluride/ cadmium Sulfide Quantum Dots under Neutral-pH Condition for Biological Applications. J. Colloid Interface Sci. 2013, 390, 3-10.

(11) Nguyen, K. C.; Willmore, W. G.; Tayabali, A. F. Cadmium Telluride Quantum Dots Cause Oxidative Stress Leading to Extrinsic and Intrinsic Apoptosis in Hepatocellular Carcinoma HepG2 Cells. Toxicology 2013, 306, 114-123.

(12) Bottrill, M.; Green, M. Some Aspects of Quantum Dot Toxicity. Chem. Commun. (Cambridge, U. K.) 2011, 47, 7039-7050.

(13) Chan, W. C. W.; Maxwell, D. J.; Gao, X.; Bailey, R. E.; Han, M.; Nie, S. Luminescent Quantum Dots for Multiplexed Biological Detection and Imaging. Curr. Opin. Biotechnol. 2002, 13, 40-46.

(14) Nagy, A.; Steinbrück, A.; Gao, J.; Doggett, N.; Hollingsworth, J. A.; Iyer, R. Comprehensive Analysis of the Effects of CdSe Quantum Dot Size, Surface Charge, and Functionalization on Primary Human Lung Cells. ACS Nano 2012, 6, 4748-4762.

(15) Nagy, A.; Hollingsworth, J. A.; Hu, B.; Steinbrück, A.; Stark, P. C.; Rios Valdez, C.; Vuyisich, M.; Stewart, M. H.; Atha, D. H.; Nelson, B. C.; et al. Functionalization-Dependent Induction of Cellular Survival Pathways by CdSe Quantum Dots in Primary Normal Human Bronchial Epithelial Cells. ACS Nano 2013, 7, 8397-8411.

(16) Casas, J. S.; García-Tasende, M. S.; Sánchez, A.; SánchezGonzález, Á.; Sordo, J.; Touceda, Á.; Vázquez-González, M. Synthesis, Characterization and in Vitro Toxicity Assessment of DMPS-Capped CdTe Quantum Dots. Polyhedron 2014, 70, 77-84.

(17) Liu, J.; Hu, R.; Liu, J.; Zhang, B.; Wang, Y.; Liu, X.; Law, W.-C.; Liu, L.; Ye, L.; Yong, K.-T. Cytotoxicity Assessment of Functionalized $\mathrm{CdSe}, \mathrm{CdTe}$ and InP Quantum Dots in Two Human Cancer Cell Models. Mater. Sci. Eng., C 2015, 57, 222-231.

(18) Winnik, F. M.; Maysinger, D. Quantum Dot Cytotoxicity and Ways to Reduce It. Acc. Chem. Res. 2013, 46, 672-680.

(19) Özel, R. E.; Liu, X.; Alkasir, R. S. J.; Andreescu, S. Electrochemical Methods for Nanotoxicity Assessment. TrAC, Trends Anal. Chem. 2014, 59, 112-120.
(20) L’Azou, B.; Passagne, I.; Mounicou, S.; Tréguer-Delapierre, M.; Puljalté, I.; Szpunar, J.; Lobinski, R.; Ohayon-Courtès, C. Comparative Cytotoxicity of Cadmium Forms $(\mathrm{CdCl} 2, \mathrm{CdO}, \mathrm{CdS}$ Micro- and Nanoparticles) in Renal Cells. Toxicol. Res. 2014, 3, 32-41.

(21) Wang, G.; Zhang, J.; Dewilde, A. H.; Pal, A. K.; Bello, D.; Therrien, J. M.; Braunhut, S. J.; Marx, K. A. Understanding and Correcting for Carbon Nanotube Interferences with a Commercial LDH Cytotoxicity Assay. Toxicology 2012, 299, 99-111.

(22) Lupu, A. R.; Popescu, T. The Noncellular Reduction of MTT Tetrazolium Salt by $\mathrm{TiO}_{2}$ Nanoparticles and Its Implications for Cytotoxicity Assays. Toxicol. In Vitro 2013, 27, 1445-1450.

(23) Wang, S.; Yu, H.; Wickliffe, J. K. Limitation of the MTT and XTT Assays for Measuring Cell Viability due to Superoxide Formation Induced by Nano-Scale TiO2. Toxicol. In Vitro 2011, 25, 2147-2151.

(24) Seiffert, J. M.; Baradez, M.-O.; Nischwitz, V.; Lekishvili, T.; Goenaga-Infante, H.; Marshall, D. Dynamic Monitoring of Metal Oxide Nanoparticle Toxicity by Label Free Impedance Sensing. Chem. Res. Toxicol. 2012, 25, 140-152.

(25) Otero-González, L.; Sierra-Alvarez, R.; Boitano, S.; Field, J. A. Application and Validation of an Impedance-Based Real Time Cell Analyzer to Measure the Toxicity of Nanoparticles Impacting Human Bronchial Epithelial Cells. Environ. Sci. Technol. 2012, 46, 1027110278.

(26) Pandey, A.; Chouhan, R. S.; Gurbuz, Y.; Niazi, J. H.; Qureshi, A S. Cerevisiae Whole-Cell Based Capacitive Biochip for the Detection of Toxicity of Different Forms of Carbon Nanotubes. Sens. Actuators, $B$ 2015, 218, 253-260.

(27) Hondroulis, E.; Liu, C.; Li, C.-Z. Whole Cell Based Electrical Impedance Sensing Approach for a Rapid Nanotoxicity Assay. Nanotechnology 2010, 21, 315103.

(28) Sticker, D.; Rothbauer, M.; Charwat, V.; Steinkühler, J.; Bethge, O.; Bertagnolli, E.; Wanzenboeck, H. D.; Ertl, P. Zirconium Dioxide Nanolayer Passivated Impedimetric Sensors for Cell-Based Assays. Sens. Actuators, B 2015, 213, 35-44.

(29) Moe, B.; Gabos, S.; Li, X.-F. Real-Time Cell-Microelectronic Sensing of Nanoparticle-Induced Cytotoxic Effects. Anal. Chim. Acta 2013, 789, 83-90.

(30) Male, K. B.; Lachance, B.; Hrapovic, S.; Sunahara, G.; Luong, J. H. T. Assessment of Cytotoxicity of Quantum Dots and Gold Nanoparticles Using Cell-Based Impedance Spectroscopy. Anal. Chem. 2008, 80, 5487-5493.

(31) Male, K. B.; Hamzeh, M.; Montes, J.; Leung, A. C. W.; Luong, J. H. T. Monitoring of Potential Cytotoxic and Inhibitory Effects of Titanium Dioxide Using on-Line and Non-Invasive Cell-Based Impedance Spectroscopy. Anal. Chim. Acta 2013, 777, 78-85.

(32) Wu, C.; Shi, L.; Li, Q.; Jiang, H.; Selke, M.; Ba, L.; Wang, X. Probing the Dynamic Effect of Cys-CdTe Quantum Dots toward Cancer Cells in Vitro. Chem. Res. Toxicol. 2010, 23, 82-88.

(33) Yoon, O. J.; Kim, C. H.; Sohn, I.-Y.; Lee, N.-E. Toxicity Analysis of Graphene Nanoflakes by Cell-Based Electrochemical Sensing Using an Electrode Modified with Nanocomposite of Graphene and Nafion. Sens. Actuators, B 2013, 188, 454-461.

(34) Kim, T.-H.; El-Said, W. A.; Choi, J.-W. Highly Sensitive Electrochemical Detection of Potential Cytotoxicity of CdSe/ZnS Quantum Dots Using Neural Cell Chip. Biosens. Bioelectron. 2012, 32, 266-272.

(35) Bull, H.; Murray, P. G.; Thomas, D.; Fraser, A. M.; Nelson, P. N. Acid Phosphatases. Mol. Pathol. 2002, 55, 65-72.

(36) Bozzo, G. G.; Raghothama, K. G.; Plaxton, W. C. Structural and Kinetic Properties of a Novel Purple Acid Phosphatase from Phosphate-Starved Tomato (Lycopersicon Esculentum) Cell Cultures. Biochem. J. 2004, 377, 419-428.

(37) Hassan, S. S. M.; Sayour, H. E. M.; Kamel, A. H. A SimplePotentiometric Method for Determination of Acid and Alkaline Phosphatase Enzymes in Biological Fluids and Dairy Products Using a Nitrophenylphosphate Plastic Membrane Sensor. Anal. Chim. Acta 2009, 640, 75-81.

(38) Friedrich, J.; Eder, W.; Castaneda, J.; Doss, M.; Huber, E.; Ebner, R.; Kunz-Schughart, L. A. A Reliable Tool to Determine Cell 
Viability in Complex 3-D Culture: The Acid Phosphatase Assay. J. Biomol. Screening 2007, 12, 925-938.

(39) Putnam, K. P.; Bombick, D. W.; Doolittle, D. J. Evaluation of Eight in Vitro Assays for Assessing the Cytotoxicity of Cigarette Smoke Condensate. Toxicol. In Vitro 2002, 16, 599-607.

(40) O’Hara, T.; Seddon, B.; McClean, S.; Dempsey, E. TOXOR: Design and Application of an Electrochemical Toxicity Biosensor for Environmental Monitoring. Electroanalysis 2015, 27, 58-66.

(41) Yan, M.; Zhang, Y.; Xu, K.; Fu, T.; Qin, H.; Zheng, X. An in Vitro Study of Vascular Endothelial Toxicity of CdTe Quantum Dots. Toxicology 2011, 282, 94-103.

(42) Vaishnavi, E.; Renganathan, R. CdTe Quantum Dot as a Fluorescence Probe for Vitamin B(12) in Dosage Form. Spectrochim. Acta, Part A 2013, 115, 603-609.

(43) Lovrić, J.; Bazzi, H. S.; Cuie, Y.; Fortin, G. R. A.; Winnik, F. M.; Maysinger, D. Differences in Subcellular Distribution and Toxicity of Green and Red Emitting CdTe Quantum Dots. J. Mol. Med. (Heidelberg, Ger.) 2005, 83, 377-385.

(44) Derfus, A. M.; Chan, W. C. W.; Bhatia, S. N. Probing the Cytotoxicity of Semiconductor Quantum Dots. Nano Lett. 2004, 4 (1), $11-18$.

(45) Liu, Y.; Chen, W.; Joly, A. G.; Wang, Y.; Pope, C.; Zhang, Y.; Bovin, J.-O.; Sherwood, P. Comparison of Water-Soluble CdTe Nanoparticles Synthesized in Air and in Nitrogen. J. Phys. Chem. B 2006, 110, 16992-17000.

(46) El-Nahass, M. M.; Youssef, G. M.; Noby, S. Z. Structural and Optical Characterization of CdTe Quantum Dots Thin Films. J. Alloys Compd. 2014, 604, 253-259.

(47) Zhu, Y.; Li, Z.; Chen, M.; Cooper, H. M.; Lu, G. Q.; Xu, Z. P. Synthesis of Robust Sandwich-Like SiO $2 @$ CdTe@SiO 2 Fluorescent Nanoparticles for Cellular Imaging. Chem. Mater. 2012, 24, 421-423.

(48) Zhang, T.; Hu, Y.; Tang, M.; Kong, L.; Ying, J.; Wu, T.; Xue, Y.; $\mathrm{Pu}, \mathrm{Y}$. Liver Toxicity of Cadmium Telluride Quantum Dots (CdTe QDs) Due to Oxidative Stress in Vitro and in Vivo. Int. J. Mol. Sci. 2015, 16, 23279-23299.

(49) Wang, T.; Jiang, X. Size-Dependent Stability of WaterSolubilized CdTe Quantum Dots and Their Uptake Mechanism by Live HeLa Cells. ACS Appl. Mater. Interfaces 2013, 5, 1190-1196.

(50) Su, Y.; Hu, M.; Fan, C.; He, Y.; Li, Q.; Li, W.; Wang, L.; Shen, P.; Huang, Q. The Cytotoxicity of CdTe Quantum Dots and the Relative Contributions from Released Cadmium Ions and Nanoparticle Properties. Biomaterials 2010, 31, 4829-4834.

(51) Fröhlich, E. Cellular Elimination of Nanoparticles. Environ. Toxicol. Pharmacol. 2016, 46, 90-94. 